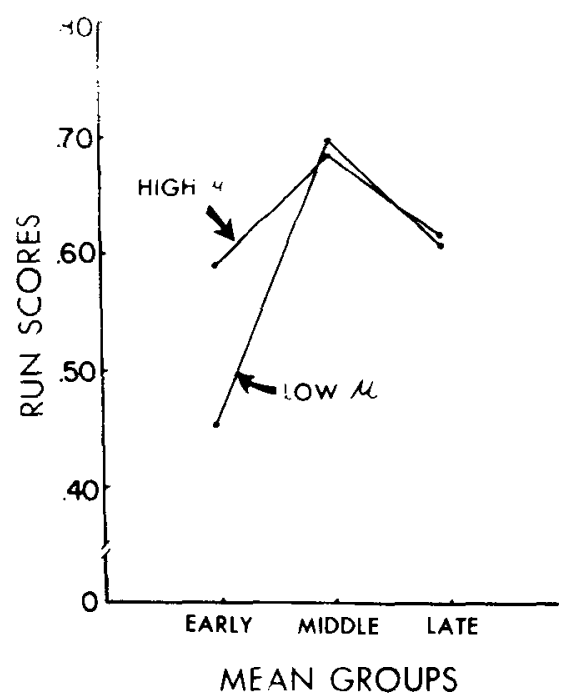

\section{DISCUSSION}

As was observed before, early run scores for all groups are significantly lower than either intermediate or late run scores. This is to be expected in that the optimal strategy for each $S$ is still weighted heavily for the prediction of the previous event, particularly so due to the random nature of the length of runs. Indeed, this is an essential feature of the k-span model of Burke \& Estes (1957), where $S$ bases his response on any one event as a result of the last $k$ events. The early run scores for the shorter run length groups were significantly lower than those of the groups exposed to longer run lengths, while no significant differences were noted in the late run scores between the groups. It would seem, then, that there is a tendency on the part of the short run groups to perseverate the response favorable to the last tone run heard.

As was suggested by Gambino \& Myers (1966), designs employing feedback techniques increase the number of reinforcements for the prediction of the alternate event for the short run groups. In the present context, feedback to $S$ was eliminated with the net effect that differences in recency disappeared between groups with different mean run lengths. This seems to support the conclusion that the differential amount of reinforcement between groups is responsible for differences in recency formerly attributed to mean run length. However, this conclusion may be more relevant to detection psychophysics than to probability learning experiments, due to the notable lack of explicit reinforcement. Perhaps the most salient feature in the results of the nonfeedback design is the increased negative recency effect with the high variability groups. It would appear that an S operating under uncertainty due to both the stimulus

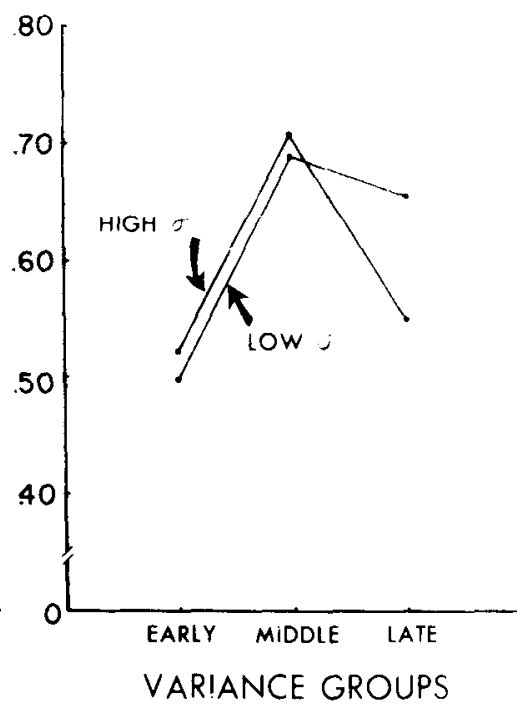

and run stability seems to choose a strategy involving the selection of the alternate event to an increasing degree shortly after the mean of the run length distribution. As an extension of the work of Verplanck, Collier, \& Cotton (1952) with sequential dependencies, the concept of negative recency in probabilistic learning models may be directly associated with the declining critical ratios reported by these authors. They found statistically significant nonindependence when as many as 10 responses intervened between correlated responses. This appears to be an accurate observation for relatively stable run sequences. However, as the variability of the run lengths increases, there is a decline in the sequential dependencies. In a later study by Collier \& Verplanck (1958), the degree of dependency in run sequences was found to be directly associated with the relative
Fig. 1. Interaction of mean and variability groups as a function of run position.

strength of the stimulus. In the traditional two-choice probability learning situation, $S$ is presented with what might be considered to be a relatively strong stimulus in the context of a detection experiment. It would seem, then, that the sequential dependencies reported in the psychophysical literature are extensions of effects found in the context of probability learning experiments.

\section{REFERENCES}

BURKE, C. J., \& ESTES, W. K. A componen model for stimulus variables in discrimination learning. Psychometrika, 1957, 22, 133-145.

COLLIER, G., \& VERPLANCK, w. S Nonindependence of successive responses at the visual threshold as a function of interpolated stimuli. Journal of Experimental Psychology, $1958,55,429-437$

GAMBINO, B., \& MYERS, J. L. Effect of mean and variability of event run length on two-choice learning. Journal of Experimental Psychology, 1966, 73, 56-67.

JAR VIK, M. E. Probability learning and a negative recency effect in the serial anticipation of alternate events. Journal of Experimental Psychology, 1951, 41, 291-297.

JONES, M. R., \& MYERS, J. L. A comparison of two methods of event randomization in probability learning. Journal of Experimental Psychology, 1966, 72, 909-911.

KINCHLA, R. A. A learning factor in visual discrimination. In R. C. Atkinson (Ed.), Studies in mathematical psychology. Stanford, Calif: Stanford University Press, 1964. Pp. 233-249.

VERPLANCK, W. S., COLLIER, G. H., \& COTTON, J. W. Nonindependence of successive responses in measurements of the visual threshold. Journal of Experimental Psychology, 1952, 44, 273-282. NOTE

1. Now at Psychology Department, Box 8185 , University of Miami, Coral Gables, Florida 33124 . Reprint requests should be addressed to $\mathrm{Dr}$. Newman.

\title{
Sound coding in verbal learning with and without restrictions on decoding
}

\section{WILLIAM E. FORRESTERI and NORMAN E. SPEAR, Rutgers University, New Brunswick, N.J. 08903}

A transfer design was used to assess the hypothesis that Ss may encode response terms as pronounceable sounds in learning a paired-associates list. The results indicated that the facilitative effects of sound coding are greatly diminished if $S$ must use different

\section{decoding rules in learning original and transfer lists.}

Underwood \& Erlebacher (1965, Experiment 6) provided evidence that response items in a verbal-learning task may be encoded as pronounceable sounds even though $S$ s are required to spell responses aloud at recall. The procedures used to demonstrate this coding process conformed 
(1) a transic design un which experimental Ss who conded first-list responses as sounds could mediate via the coded item in learning second-list pairs. Thus, if S learned 3-AKE as a pair in List $\mathrm{l}$ and coded the response as ak the coded form of the item could be used as a mediator in learning the pair 3-ACHE in List 2. As Underwood and Erlebacher point out. interference could arise from the difference in decoding processes required in producing first- and second-list responses. Their results indicated, nevertheless, that the facilitative effects of sound coding were sufficiently great to outweigh any interference at decoding and, thus, produce a small net positive-transfer effect.

In the present study, an attempt was made to assess the magnitude of the interference effect associated with the decoding process. For this reason, a factorial design was used in which $\mathrm{Ss}$ in one condition were not required to decode at recall; that is, $S$ was instructed to pronounce rather than to spell responses. Ss in the other condition were required, as in Underwood \& Erlebacher's study, to decode (i.e., spell) responses. It was expected that positive transfer effects would occur in both experimental conditions, relative to appropriate control groups, but a greater effect was expected under conditions not requiring decoding. In short, an in teraction was predicted between experimentalcontrol and spell-pronounce factors.

SUBJECTS AND MATERIALS

A total of 72 male undergraduates at Rutgers volunteered to serve in the study. All Ss were enrolled in introductory psychology classes and had not served in any previous verbal learning experiments.

All lists used were taken from Underwood \& Erlebacher (1965, Experiment 6). Two different eight-item lists were used as List 1. Response terms for the experimental (E) list were eight trigrams which had previously been judged to be highly similar in pronunciation to the words used as responses in the transfer list. Control (C) list responses were trigrams which had been judged to be distinctly different in pronunciation from the List 2 words. The $\mathrm{E}$ and $C$ list items were chosen so that they corresponded in terms of formal similarity with List 2 responses. For example, the trigram SEY was in the E list, while the corresponding $C$ list trigram was SIY. The List 2 word corresponding to both of these trigrams was SAY.

Each of the trigrams in List 1 was paired with a number from 1 to 9 ( 8 was excluded), and corresponding trigrams from the two lists were paired with the same number. The same stimulus terms were used for List 2 with each number being paired with a word in the second list and its corresponding trigram in the first list.

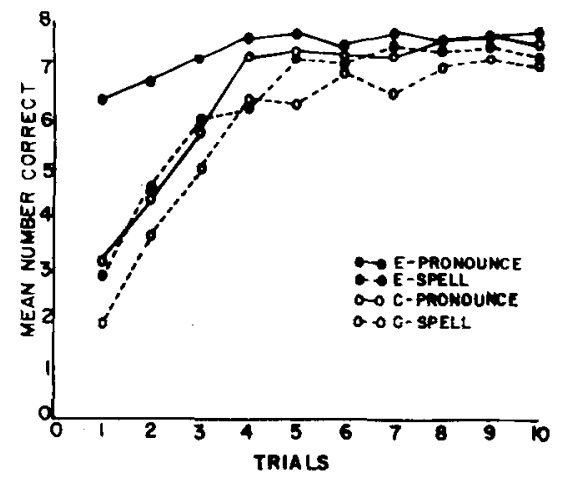

Fig. 1. Mean number correct across 10 transfer trials.

\section{DESIGN AND PROCEDURES}

A 2 by 2 factorial transfer design was used with the variables being task (spell vs pronounce) and first list ( $E$ vs $C$ ). The Ss were assigned to conditions $(n=18)$ on the basis of a randomized schedule sheet and S's order of appearance in the laboratory.

All Ss were required to learn List 1 to a criterion of one perfect recitation of the list on a single trial. List 2 was presented for one study and 10 anticipation trials after an interval of approximately $1 \mathrm{~min}$ following completion of List 1 learning. The presentation rate for both lists was $2: 2 \mathrm{sec}$, with an intertrial interval of $4 \mathrm{sec}$. Five randomized orders of the pairs were used for each list, and they were the same for all conditions as defined by the stimulus terms. For the pronounce condition, a correct response was determined on the basis of E's judgment and S's consistency across trials. RESULTS AND DISCUSSION

The mean number of trials to criterion in List 1 learning ranged from 11.06 to 13.78 , the between-groups F being 1.34. The groups were thus comparable in learning of the first list. The lack of significant differences between pronounce and spell conditions is some what surprising in view of the presumed difference in task difficulty. If, however, the assumption that Ss sound code is valid, these results could indicate that decoding was a relatively simple matter for those Ss in the spell condition.

Acquisition curves across the 10 trials of the transfer list are shown in Fig. 1. As can be seen, there was a marked superiority of Group E-Pronounce over the other three groups on the initial trials. An analysis of variance was performed on the mean number of items correct on the first two transfer trials. The predicted interaction was significant $[F(1,68)=5.67, p<.05]$, as were both main effects. In view of the significant interaction, simple effects were evaluated for the E-C variable under spell and pronounce conditions. Using the within-groups variance from the overall analy sis 10 determine the crror term, it was found that the E-C difference was significant under pronounce conditions $\mathrm{f}=5.25$. $\mathrm{p}<.001$ ), but fell short of significance under spell conditions $(1=1.89$, with 2.03 needed for $p=.05$ ). While the latter comparison failed to show statistical significance, the absolute difference in means between E-spell and C-spell (2.05 items) was actually larger than that reported by Underwood \& Erlebacher (1965, Experiment 6), who obtained a mean difference of 1.95 items and a t of 2.19. The discrepancy in results appears to be due to slightly greater within-groups variability in the present study.

While the predicted interaction was found early in transfer performance, it was not significant in the analysis of total correct across the 10 transfer trials. The latter analysis did show, however, that both main effects were significant at the .001 level. The respective Fs for spell-pronounce and E-C factors were 18.55 and 14.46. Individual comparisons of $\mathrm{E}$ and $\mathrm{C}$ groups showed $t=3.16 \quad(p<.01) \quad$ under pronounce conditions, and $t=2.21 \quad(p<.05)$ under spell conditions. Overall differences in the pronounce condition appear to be due to the initial superiority of $\mathbf{E}$ over $\mathbf{C}$. Differences between E-spell and C-spell, on the other hand, were smaller but consistent over all 10 trials.

The present results may be interpreted on the basis of interference effects arising at recall when sound-coded responses must be decoded. As indicated previously, the lack of significant differences between pronounce and spell conditions in List 1 learning suggests that if $S s$ in the latter groups did sound-code, they had little difficulty in decoding. In Leaming List 2, however, Ss in Group E-Spell had to learn a new decoding rule if they used sound as a mediator. The extent to which interference at decoding subtracts from any positive effects of sound coding was revealed by the interaction found on the initial transfer trials. While the E-C differences were considerable for pronounce groups, interference at decoding reduced the differences between the corresponding spell groups. With regard to the differences between E-Spell and C-Spell conditions, the present data are in accord with Underwood and Erlebacher's conclusion that the positive effects of sound coding are relatively small.

REFERINCES

UNDI:RWOOD B. J \& ERIEBACHI:R, A. H Studies of coding in verbal learning. Psychological Monographs, 1965, 79(13, Whole No. 606).

\section{NOTE:}

1. Now at State University of Niw York. Oswego. New York 13126. 